\title{
Association of the JAZF1 Variant in Adults With a Parental History of Type 2 Diabetes Mellitus In Pakistan
}

\author{
Sheh Zano ${ }^{1}$, Zil E. Rubab ${ }^{1}$, Saeeda Baig ${ }^{1}$, Moazzam A. Shahid ${ }^{1}$, Farah Ahmad $^{2}$, Faizan Iqbal $^{3}$ \\ 1. Biochemistry, Ziauddin University, Karachi, PAK 2. Community Health Sciences, Ziauddin University, Karachi, PAK \\ 3. Orthopaedics, Patel Hospital, Karachi, PAK
}

Corresponding author: Sheh Zano, shehzano@zu.edu.pk

\section{Abstract \\ Background}

Type 2 diabetes mellitus (T2DM) is a chronic multifactorial condition and quickly growing disease in Pakistan. Many genes together with Zinc finger protein 1 (JAZF1) have already been described earlier in the literature but the role of JAZF1 in this subset of the population is yet to define. This study was aimed at identifying JAZF1 polymorphism and the risk of developing T2DM in persons with a parental history of T2DM in the Pakistani population.

\section{Methods}

DNA samples from 75 non-diabetic Pakistani participants with a family history of T2DM and 75 controls were evaluated by using a polymerase chain reaction (PCR) and the restriction fragment length polymorphism method.

\section{Results}

The alleles AA and AG and the GG genotype of JAZF1 (rs864745) varied considerably in frequency distribution between cases and control $(\mathrm{p}<0.05)$. The GG was independently and significantly associated with cases who had a family history of T2DM [odds ratio (OR) 2.6 (95\% confidence interval (Cl) $1.3-5.1$ ); $\mathrm{p}=0.005$ ] while the AA allele was significantly associated with controls without a family history of T2DM [odds ratio (OR) 0.39 (95\% confidence interval $(\mathrm{Cl}) 0.2-0.7)$; $\mathrm{p}=0.0059$ ] and the allele AG has no significance and was equally distributed among control and cases with $\mathrm{p}$-value $=1.000$.

\section{Conclusion}

Genotype GG of the JAZF1 variant was found significantly associated with the risk of developing type 2 diabetes mellitus in the Pakistani subset of the population.

Review began $11 / 17 / 2020$ Review ended 11/28/2020 Published 12/06/2020

\section{() Copyright 2020}

Zano et al. This is an open access article distributed under the terms of the Creative Commons Attribution License CC-BY 4.0., which permits unrestricted use, distribution, and reproduction in any medium, provided the original author and source are credited.
Categories: Endocrinology/Diabetes/Metabolism, Genetics, Other

Keywords: type 2 diabetes mellitus, multifactorial inheritance, jazf1, family history, genetic variant, systemic, pakistani population

\section{Introduction}

Type 2 diabetes mellitus (T2DM) is a systemic disease that is indicated by increasing blood sugar levels and is secondary to defect either in insulin production or insulin resistance [1]. Diabetes mellitus is a primary health concern in Pakistan [2-4]. Previously, the prevalence of type 2 diabetes mellitus was related to an abundance of wealth, urbanization, and a sedentary lifestyle. Type 2 diabetes mellitus is more prevalent in middle and low-income countries like Pakistan [5-7]. According to the World Bank's country classification, Pakistan is a lower-middle-income country [8]. Pakistan is the sixth most densely populated country in the world and the prevalence of type 2 diabetes mellitus is still underestimated [9]. The International Diabetes Federation (IDF) reported that the overall prevalence of T2DM in Pakistan was $6.8 \%$ in patients aged between 20 and 79 years [10]. Previous studies also show some disagreement about the results reported by the IDF, and they found that the prevalence of T2DM is found to be $7.2 \%$ to $19.2 \%$ in different regions of Pakistan [11].

Besides lifestyle and environmental risk factors, type 2 diabetes mellitus also has an established genetic predisposition [12]. Risk factors, reported by multiple studies in the development of type 2 diabetes mellitus, include obesity, hypertension, hypercholesterolemia, along with a parental history of T2DM [13].

JAZF1 encodes a putative transcription factor that interacts with protein NR2C2 (nuclear receptor subfamily 2, group C, member 2 - also referred to as TR4 orphan nuclear receptor) and inhibits transactivation that 
targets many essential genes in metabolism. Impaired function of beta cells has been correlated with JAZF1 locus variants as a gene transcriptional repressor that negatively influences the metabolism of glucose, which emphasizes that these susceptibility alleles may result in a decreased transcription of JAZF1. Such mutants like rs1635852, rs849133, and rs849142, rs1635852, and 864745 have already been linked with T2DM [13]. SNP rs 864745 has been found to be more prevalent in our population; therefore, it is considered in our study [14].

However, not only are the data regarding the association of the rs864745 variant of JAZF1 limited but also its relationship with parental history is not established. The purpose of this case-control study was to identify the polymorphism of the JAZF1 variant (rs864745) as an additional threat of developing T2DM, especially in patients who had a parental history of T2DM.

\section{Materials And Methods}

\section{Patient selection}

The sample size was calculated by using OpenEpi software (www.OpenEpi.com) with a two-sided confidence level (1-alpha) 95 and power of 80 with a hypothetical proportion of cases with exposure 24.56. A total of 150 participants (75 non-diabetics with a parental history of T2DM and 75 healthy controls with no parental history) belonging to the same demographic features were enrolled. The diagnosis of T2DM was based on World Health Organization (WHO) guidelines (fasting glucose levels as low as $126 \mathrm{mg} / \mathrm{dl}$ or as low as 7.0 $\mathrm{mmol} / \mathrm{L}$ ). All consenting participants were given a generalized questionnaire, including demographics and past medical history. Excluded from this study were those patients with comorbidities such as type 2 diabetes and type 1 diabetes. Control subjects $(n=75)$ with the usual fasting blood sugar (FBS) value were identified from the age and gender-based general population.

Five $\mathrm{ml}$ of fasting blood samples were taken from subjects, $3 \mathrm{~mL}$ was taken in ethylenediaminetetraacetic acid (EDTA) tubes for molecular analysis, and the other $2 \mathrm{ml}$ in a gray-top tube for FBS. After the extraction of deoxyribonucleic acid (DNA) and FBS analysis, the samples were stocked at $-80^{\circ}$.

\section{Clinical and chemical assessments}

Clinical and anthropometric parameters were recorded, including weight (kg), height (m), blood group, ethnicity, family history, marital status duration of diabetes Body mass index (BMI). Fasting blood glucose (FBG) is measured using a Glucose- GOD-PAP enzymatic colorimetric method.

\section{DNA extraction}

Whole blood was used to extract deoxyribonucleic acid (DNA) (Genomic) using a DNA isolation kit (GeNet Bio Prime Prep ${ }^{\mathrm{TM}}$ Genomics, Korea) by adding 20 ul proteinase K solution in an Eppendorf tube. After that, $200 \mathrm{ul}$ of blood was added to it and then $200 \mathrm{ul} \mathrm{GB}$ buffer. This was then vortexed for $15 \mathrm{sec}$, incubated at $56^{\circ} \mathrm{C}$ for $10 \mathrm{~min}$, and $200 \mathrm{ul}$ absolute ethanol was then added and vortexed for $15 \mathrm{sec}$. We carefully transferred the lysate into the upper reservoir of the spin column, centrifuged it at 8000 rpm for 1 minute, and then transferred the spin column to a new collection tube for filtration. Five-hundred ul of buffer GW1 was added to the spin column and centrifuges at $8000 \mathrm{rpm}$ for one min. After which, the flow-through was discarded and the spin column was transferred to a new collection tube. Five-hundred ul of the GW2 buffer was added to the spin column and centrifuged at $8000 \mathrm{rpm}$ for $1 \mathrm{~min}$, after which the flow-through was discarded. The spin-column was reassembled with its collection tube, centrifuged one more time at 12000 rpm for one to two min to completely remove ethanol. Finally, the spin column was transferred to a new tube for elusion. Then, $200 \mathrm{ul} \mathrm{GE}$ buffer was added into the spin column. After waiting for $1 \mathrm{~min}$ at room temperature and centrifuging at $8000 \mathrm{rpm}$ for one $\mathrm{min}$, the flow-through was collected and stored at $-80^{\circ} \mathrm{C}$. Nanodrop and gel electrophoresis was used to evaluate the quantity and quality of DNA.

\section{Analysis of genotyping polymorphism by polymerase chain reaction (PCR) and restriction fragment length polymorphism (RFLP)}

JAZF1 polymorphism for 378 bp DNA fragments was done by polymerase chain reaction by using the following primer:

forward (A > G) 5'-GAGCCATATAAGTGATGCTCAAA-3' (Alharbi KK et al., 2015 [15])

reverse 5'-GGTTGTCAGGCTTTCCATGT-3' (Alharbi KK et al., 2015 [15])

PCR was programmed with an initial denaturation at $95^{\circ} \mathrm{C}$ for five minutes, followed by 40 cycles of denaturation at $95^{\circ} \mathrm{C}$ for $30 \mathrm{sec}$, annealing at $58^{\circ} \mathrm{C}$ for $30 \mathrm{sec}$, and extension at $72{ }^{\circ} \mathrm{C}$ for $40 \mathrm{sec}$. PCR was then followed by RFLP in which restriction endonuclease (Thermo Scientific \#ER0771; Waltham,

Massachusetts) 2 UL SSPI was used to digest the $10 \mu \mathrm{L}$ PCR product, 18 ul nuclease-free water, and 10x buffer $\mathrm{G}$ mix gently, and this was incubated at $16 \mathrm{~h}$ at $37^{\circ} \mathrm{C}$ for A allele (378bp), for $\mathrm{G}$ allele (338 and 40 -bp), and AG allele (378 bp, 338 bp, $40 \mathrm{bp}$ ). Gel electrophoresis was used to visualize in which 1-2 gm of agarose 


\section{Cureus}

was used according to the need in each gel, with a voltage of $110 \mathrm{amp}$ for 40 minutes.

\section{Statistical analysis}

The Statistical Package for the Social Sciences (SPSS) version 25.0 (IBM Corp., Armonk, NY) was used for the analysis of data. Data regarding numerical variables are mentioned as mean \pm standard deviation. Chi-square was used as the test of significance for genotype frequency between cases and controls for each single nucleotide polymorphisms (SNPs). For inter and intragroup comparison of genotype with age, BMI, and FBS between cases and controls. Analysis of variance (ANOVA) was applied as the test of significance. Bivariate analysis was carried out for finding the association of genes with cases and controls and was reported as an odds ratio. p-value $<0.05$ was considered significant at a $95 \%$ confidence interval.

\section{Results}

The demographic characteristics of the study participants listed in Table 1 show the most participants of our study were in the age group of 18-23 with a frequency of 57 (38\%). Gender was equally distributed in our study. Urdu speaking ethnicity was predominant $(53 ; 35.3 \%)$ while further results are elaborated in Table 1.

\begin{tabular}{|c|c|c|}
\hline VARIABLES & CONTROL & CASE \\
\hline \multicolumn{3}{|l|}{ Age } \\
\hline $18-23$ & $33(44 \%)$ & $24(32 \%)$ \\
\hline $24-28$ & $20(26.7 \%)$ & $29(38.7 \%)$ \\
\hline $29-33$ & 14 (18.7\%) & $12(13.3 \%)$ \\
\hline $34-38$ & $8(10.7 \%)$ & $10(13 \%)$ \\
\hline \multicolumn{3}{|l|}{ Gender } \\
\hline Male & $35(46.7 \%)$ & $40(53.3 \%)$ \\
\hline Female & 40 (53.3\%) & $35(46.7 \%)$ \\
\hline \multicolumn{3}{|l|}{ Marital status } \\
\hline Single & 36 (48\%) & $32(42.7 \%)$ \\
\hline Married & $39(52 \%)$ & $43(57.3 \%)$ \\
\hline \multicolumn{3}{|l|}{ Ethnicity } \\
\hline Sindhi & $10(13.3 \%)$ & $8(10.7 \%)$ \\
\hline Punjabi & $11(14.7 \%)$ & $26(34.7 \%)$ \\
\hline Pathan & $9(12.0 \%)$ & $4(5.3 \%)$ \\
\hline Baloch & $5(6.7 \%)$ & $2(2.7 \%)$ \\
\hline Urdu speaking & $27(36.0 \%)$ & $26(34.7 \%)$ \\
\hline Other & $13(17.3 \%)$ & $9(12 \%)$ \\
\hline
\end{tabular}

\section{TABLE 1: Demographic data of Pakistani participants}

In Table 2, we determine the association between the JAZF1 variant and T2DM risk factors by using analysis of variance (ANOVA) after controlling for threats like age, BMI, and FBS. All the above risk factors are not significant in our study as the $\mathrm{p}$-value of all three risk factors is $>0.05$. 


\section{Cureus}

\section{AGE}

JAZF1 (rs864745)

CONTROL (Mean+-SD)

CASES (Mean+-SD)

AA

$25.97+-4.70$

$27.03+-4.42$

AG

$26.85+-5.39$

26.14+-4.37

GG

25.14+-3.8

$26.28+-4.31$

P-value

0.644

0.756

BMI

JAZF1 (rs864745)

CONTROL (Mean+-SD)

CASES (Mean+-SD)

\section{AA}

$24.90+-4.11$

$24.7+-3.35$

AG

$22.62+-3.32$

$26.75+-5.6$

GG

$24.07+-4.79$

$24.5+-4.0$

P-value

0.375

0.412

FBS

JAZF1 (rs864745)

CONTROL (Mean+-SD)

CASES (Mean+-SD)

AA

$79.82+-10.45$

$85.56+-11.33$

AG

$73.85+-12.78$

$77.57+-14.03$

GG

$81.42+-12.33$

$82.52+-11.14$

P-value

0.306

0.221

\section{TABLE 2: Quantitative variables according to the genotype of JAZF1 polymorphism}

BMI: body mass index; FBS: fasting blood sugar

Table 3 displays the genotype distribution for rs 864745 among people with a family history of type 2 diabetes and control subjects without a parental history of type 2 diabetes mellitus. The distribution of the AA, AG, and GG genotypes $(\mathrm{p}<0.005)$ varied significantly between cases and control. Similarly, the frequency of AA (rs864745) JAZF1 was significantly more in the control than in cases (62.6\% vs $40 \%$ ), whereas the occurrence of the AG genotype is not significant in both groups ( $9.3 \%$ vs $9.3 \%$ ) while the GG genotype was considerably more in cases than in controls ( $28 \%$ vs $50.6 \%$ ). Detailed results are elaborated on in the table. Figures 1-3 show the PCR and RFLP results of the JAZF1 gene (rs864745).

\begin{tabular}{|c|c|c|c|c|c|}
\hline JAZF1 & CONTROL & CASE & Odd ratio & p.value & C/I \\
\hline AA & $47(62.6 \%)$ & $30(40 \%)$ & 0.39 & 0.0059 & $0.2-0.7$ \\
\hline$A G$ & $7(9.3 \%)$ & $7(9.3 \%)$ & 1.00 & 1.000 & $0.3 \_3.0$ \\
\hline GG & $21(28 \%)$ & $38(50.6 \%)$ & 2.6 & 0.005 & $1.3-5.1$ \\
\hline
\end{tabular}

TABLE 3: Genotype distribution of JAZF1 variant (rs864745) in the case and control groups 


\section{Cureus}

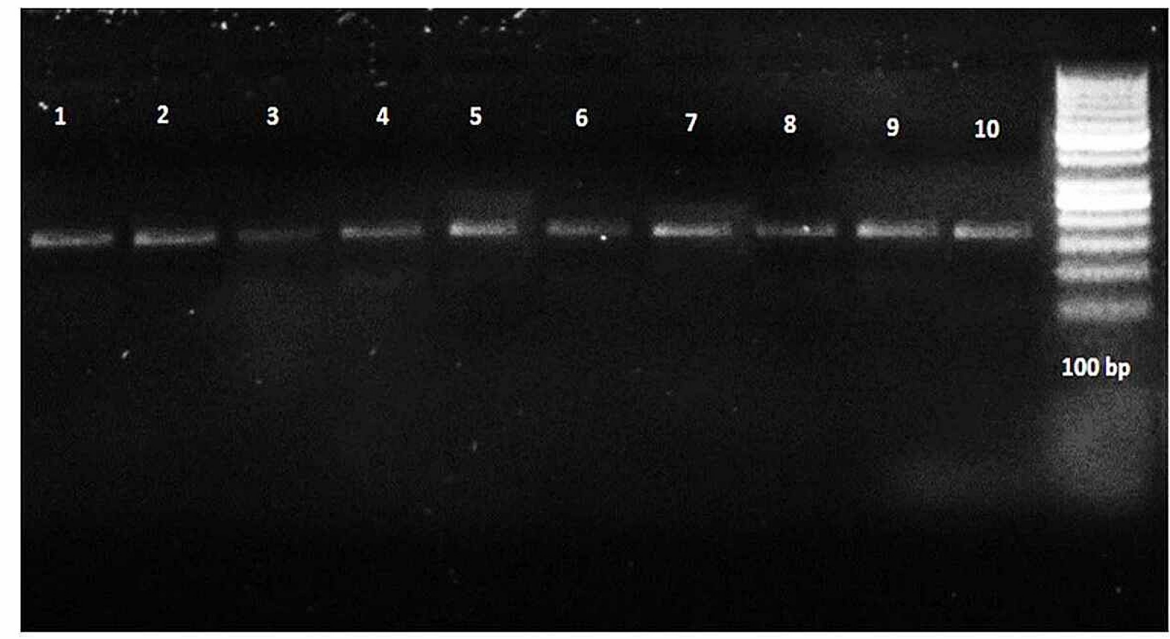

FIGURE 1: PCR results of the JAZF1 gene (rs864745)

Lane 1-10: showing the 378 bp band of the rs 864745 JAZF1 gene; Lane 11: showing the 100 bp ladder PCR: polymerase chain reaction

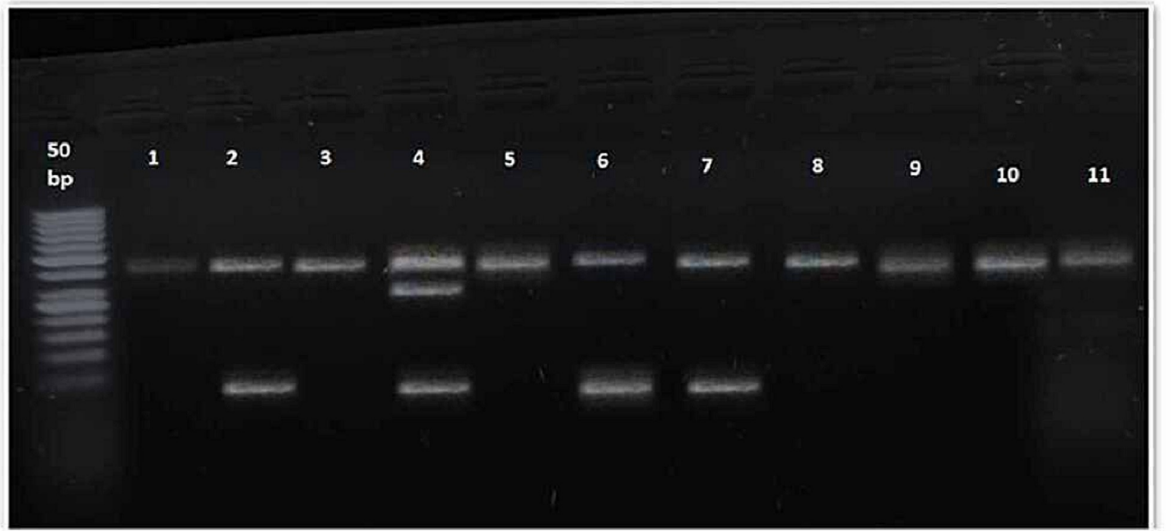

FIGURE 2: RFLP results of the control group of the JAZF1 gene (rs864745)

Lane 1, 3, 5, 8, 9, 10, and 11: showing wild type AA genotype (378 bp); Lane 2, 6, and 7 showing a homozygous mutant GG genotype (338 and 40 ); Lane 4 showing a heterozygous AG genotype $(378,338$, and $40 \mathrm{bp}$ ). The left side of the picture showing a $50 \mathrm{bp}$ ladder.

RFLP: restriction fragment length polymorphism 


\section{Cureus}

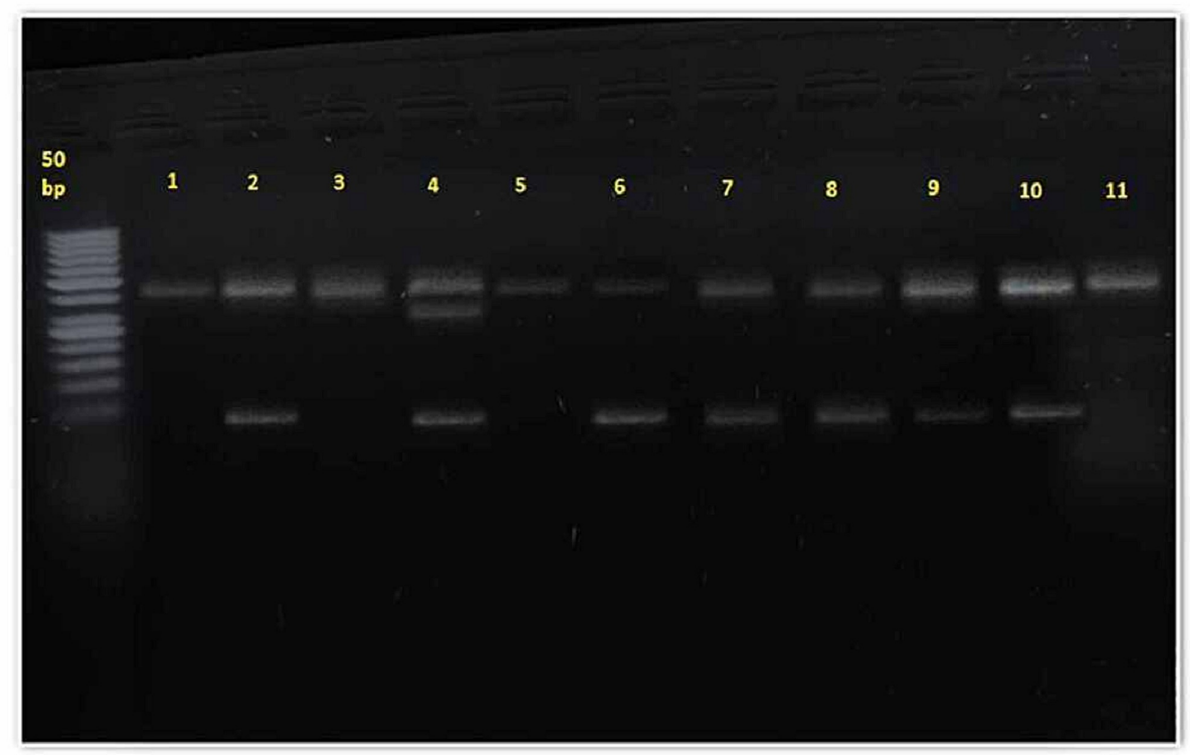

\section{FIGURE 3: RFLP results of the cases group of the JAZF1 gene (rs864745)}

Lane 1, 3, 5, and 11: showing wild type AA genotype (378 bp); Lane 2, 6, 7, 8, 9, and 10 showing a homozygous mutant GG genotype (338 and 40$)$; Lane 4 showing a heterozygous AG genotype (378, 338 , and $40 \mathrm{bp})$. The left side of the picture showing a $50 \mathrm{bp}$ ladder.

RFLP: restriction fragment length polymorphism

Table 3 displays the genotype distribution for rs 864745 among people with a family history of type 2 diabetes and control subjects without a parental history of type 2 diabetes mellitus. The distribution of the AA, AG, and GG genotypes ( $\mathrm{p}<0.005)$ varied significantly between cases and control. Similarly, the frequency AA (rs864745) JAZF1 was significantly more in the control than in cases (62.6\% vs $40 \%$ ), whereas the occurrence of the AG genotype is not significant in both the groups (9.3\% vs $9.3 \%$ ) while the GG genotype was considerably more in the cases than the controls ( $28 \%$ vs $50.6 \%)$. Detailed results are elaborated in Table 3.

\section{Discussion}

The purpose of this case-control study is to evaluate the association of the JAZF1 (rs864745) variant and the development of T2DM, especially in Pakistan. Alharbi et al. conducted a study in the Saudi population with 400 T2DM and 400 healthy subjects [15]. They found that the JAZF1 (rs864745) variant is frequently associated with T2DM with an increased waist circumference. This study was conducted in patients who were diabetic and had a parental history of diabetes. The findings of this study were similar in the sense that JAZF1 is associated with T2DM but in our study, we include non-diabetic individuals (cases) with a parental history of T2DM, which is in contrast to the study conducted in the Saudi population who were diabetic. They also found that the AG+GG genotypes are frequently associated with increased waist circumference and fasting blood glucose levels. We also found the GG genotype in non-diabetic patients who had a parental history of T2DM. Stancakova et al. conducted a study at Kuopio University Hospital, Finland, in non-diabetic Finnish men [16]. They actually failed to confirm an association with the JAZF1 (rs864745) variant.

Rees et al. conducted a case-control study in two Punjabi populations, predominantly originating from Mirpur Khas, Pakistan [17]. The authors concluded that 13 genes are associated with an increased risk of T2DM in Pakistan. On the contrary, our study includes individuals with different ethnicity and with a parental history, which might be helpful to identify high-risk individuals in different regions of our country and for early diagnosis. To the best of our knowledge, this study is the first from a single center of Karachi, Pakistan, to report the association of the JAZF1 variant and T2DM. Despite the increasing prevalence of T2DM in our country, we still lack agreement to make any firm consensus between the JAZF1 (rs864745) variant and the development of T2DM. Therefore, this study is conducted to highlight individuals (cases) with a parental history of diabetes who are at risk of developing T22DM, as early detection prevents longterm consequences of T2DM [18].

A number of studies have already been published to report results regarding the association of the JAZF1 (rs864745) variant and T2DM, especially in well-developed countries, but more studies are needed to use this 
gene as a biomarker [19]. In our study, the genotype distribution of the JAZF1 variant (rs864745) differs among cases and control subjects. We found the GG genotype more in patients who had a parental history of T2DM, whereas the AA genotype was found more commonly in control subjects. We found a statistically significant relationship between these two genotypes, as shown in Table 3 with P-value $<0.05$. The AA genotype is not found to be statistically significant in our study. Based on these findings, patients that have the GG genotype are more prone to develop type 2 diabetes mellitus. More support for the possible association between the JAZF1 (rs864745) variant and T2DM, confounding factors were evaluated between case and control subjects to identify the genotype responsible for the development of T2DM, especially in patients who had a parental history of diabetes as shown in Table 2.

Previous studies had already demonstrated the association of T2DM with body fat and BMI [20-23]. In our study, patients who had a parental history of T2DM had normal BMI and body fat distribution. Therefore, the exact association between T2DM with body fat distribution and BMI is not well-elucidated in the current study.

The present study showed that compared with normal subjects (controls), we found the GG genotype in cases that had a parental history of type 2 diabetes mellitus. The JAZF1 variant (rs864745) commonly resides in intron 1 , which actually encodes a transcriptional repressor of nuclear receptor subfamily 2 , the group C member 2 (NR2C2) gene. NR2C2 widely displays a phenotype of growth retardation, hypoglycemia, and reduced glycogenesis by decreasing the activity of PEPCK. The role of pancreatic beta-cell function has not been demonstrated yet. However, one must hypothesize that the JAZF1 variant (rs864745) also affects betacell mass and function [24-26]. Kobiita et al. conducted a study regarding the role of JAZF1 in the homeostatic control of ribosome biogenesis and function in metabolic stress. They found that SNP rs1635852 located in intron X of JAZF1 is a key factor in pancreatic beta-cell for mediating metabolic stress signals and regulating protein translation in response to increased demand for insulin [27].

Previous studies already establish the association of environmental, metabolic, and genetic roles in the development of T2DM [28-30]. Our study is unique in the sense that all cases were non-diabetic and they only had a family history of T2DM. This study highlights the subjects who are at a high risk of developing T2DM in the future. The early recognition of high-risk patients by genetic means prevents patients from the long-term consequences of T2DM. The prevalence of T2DM in a developing country like Pakistan is increasing rapidly. Therefore, this study was conducted to determine a genotype of the JAZF1 variant rs864745 in the early detection of patients who had a parental history of T2DM.

The limitation of our study is that it is conducted in a single center; therefore, the result of this study cannot be generalized for the entire population. Second, the sample size of our study is small, which compromises our findings in order to establish an association of JAZF1 in adults with a parental history of T2DM; large sample size is required. As the diagnosis of T2DM is a social stigma, and individuals suffering from it have to face lifetime problems; therefore, more studies are needed to confirm the above findings and consider this gene as a biomarker in the future.

\section{Conclusions}

Our study concluded that genotypic variants of JAZF1 rs864745 are important to identify individuals at risk of developing T2DM, and it may assist in early recognition of T2DM. People with genotype GG are at increased risk of developing type 2 diabetes mellitus in the future as compared to people with genotypes AA and $\mathrm{AG}$ in the Pakistani community.

\section{Appendices}

\begin{tabular}{|c|c|c|c|c|c|c|c|c|c|c|c|}
\hline SAMPLE & AGE & GENDER & WEIGHT & HEIGHT & BMI & BLOOD GROUP & MARRITAL STATUS & ETHNICITY & FAMILY HISTORY & FBS & JAZF1 \\
\hline cases & $29-33$ & female & 70 & 5.5 & 25 & $\mathrm{~B}+$ & married & punjabi & yes & 93 & gg \\
\hline cases & $18-23$ & male & 72 & 5.9 & 22.9 & $\mathrm{~B}+$ & single & punjabi & yes & 99 & $\mathrm{gg}$ \\
\hline cases & $18-23$ & female & 46 & 5.3 & 16.8 & $\mathrm{~B}+$ & single & punjabi & yes & 80 & $\mathrm{gg}$ \\
\hline cases & $18-23$ & female & 59 & 5.4 & 22.3 & $\mathrm{~B}+$ & single & urdu speaking & yes & 96 & $\mathrm{gg}$ \\
\hline cases & $18-23$ & female & 62 & 5.6 & 21.3 & At & single & punjabi & yes & 97 & gg \\
\hline cases & $29-33$ & female & 63 & 5.6 & 21.3 & $\mathrm{~B}+$ & married & urdu speaking & yes & 91 & gg \\
\hline cases & $18-23$ & female & 68 & 5.7 & 22.2 & $\mathrm{~B}+$ & single & urdu speaking & yes & 80 & gg \\
\hline cases & $18-23$ & male & 58 & 5.8 & 18.5 & $A+$ & single & urdu speaking & yes & 100 & $\mathrm{gg}$ \\
\hline cases & $18-23$ & female & 65 & 5.4 & 23.3 & $\mathrm{~B}+$ & single & others & yes & 98 & gg \\
\hline
\end{tabular}




\begin{tabular}{|c|c|c|c|c|c|c|c|c|c|c|c|}
\hline cases & $18-23$ & female & 55 & 5.4 & 19.7 & $\mathrm{~B}+$ & single & urdu speaking & yes & 84 & gg \\
\hline cases & $18-23$ & female & 51 & 5.2 & 19.6 & O+ & single & baloch & yes & 99 & AA \\
\hline cases & $24-28$ & male & 68 & 5.8 & 21.3 & O+ & married & sindhi & yes & 98 & AA \\
\hline cases & $24-28$ & female & 60 & 5.5 & 20.8 & $\mathrm{~B}+$ & married & sindhi & yes & 81 & AA \\
\hline cases & $34-38$ & female & 80 & 5.6 & 27 & O+ & married & urdu speaking & yes & 77 & $\mathrm{gg}$ \\
\hline cases & $24-28$ & female & 52 & 5.1 & 20.1 & O+ & married & urdu speaking & yes & 98 & gg \\
\hline cases & $34-38$ & female & 80 & 5.7 & 26.2 & $\mathrm{AB}+$ & married & punjabi & yes & 63 & $\mathrm{gg}$ \\
\hline cases & $24-28$ & male & 85 & 5.6 & 28.4 & $\mathrm{AB}+$ & married & pathan & yes & 56 & gg \\
\hline cases & $18-23$ & female & 78 & 5.1 & 26 & O+ & married & urdu speaking & yes & 84 & $\mathrm{Ag}$ \\
\hline cases & $18-23$ & male & 78 & 5.1 & 26 & $\mathrm{AB}+$ & single & urdu speaking & yes & 79 & $\mathrm{Ag}$ \\
\hline cases & $34-38$ & male & 85 & 5.11 & 25.9 & $0-$ & married & urdu speaking & yes & 64 & AA \\
\hline cases & $34-38$ & female & 82 & 5.7 & 26.6 & $\mathrm{~B}+$ & married & urdu speaking & yes & 65 & gg \\
\hline cases & $24-28$ & male & 103 & 5.8 & 31.9 & B- & married & urdu speaking & yes & 77 & gg \\
\hline cases & $24-28$ & female & 70 & 5 & 28.1 & $0-$ & married & others & yes & 78 & $\mathrm{Ag}$ \\
\hline cases & $18-23$ & male & 75 & 5.4 & 26.4 & A- & single & others & yes & 85 & $\mathrm{Ag}$ \\
\hline cases & $34-38$ & female & 82 & 5.8 & 25.4 & At & married & urdu speaking & yes & 92 & $\mathrm{Ag}$ \\
\hline cases & $29-33$ & female & 85 & 5.6 & 28.2 & A- & married & punjabi & yes & 88 & gg \\
\hline cases & $29-33$ & female & 80 & 5.8 & 25.1 & O+ & married & urdu speaking & yes & 91 & gg \\
\hline cases & $24-28$ & female & 80 & 5.8 & 25.1 & $\mathrm{~B}+$ & married & urdu speaking & yes & 76 & $\mathrm{gg}$ \\
\hline cases & $24-28$ & female & 53 & 5.4 & 18.7 & $\mathrm{~B}+$ & married & urdu speaking & yes & 59 & $\mathrm{gg}$ \\
\hline cases & $24-28$ & female & 59 & 5.1 & 17.5 & O+ & married & sindhi & yes & 77 & $\mathrm{gg}$ \\
\hline cases & $24-28$ & female & 65 & 5.5 & 23 & O+ & married & baloch & yes & 83 & gg \\
\hline cases & $29-33$ & female & 48 & 5.4 & 18 & $\mathrm{AB}+$ & married & punjabi & yes & 77 & $\mathrm{Ag}$ \\
\hline cases & $24-28$ & female & 90 & 5.12 & 37.4 & A- & married & others & yes & 48 & $\mathrm{Ag}$ \\
\hline cases & $24-28$ & male & 68 & 5.11 & 28.2 & $\mathrm{~B}+$ & single & sindhi & yes & 93 & gg \\
\hline cases & $18-23$ & male & 60 & 5.9 & 19.5 & B- & single & punjabi & yes & 87 & gg \\
\hline control & $18-23$ & female & 53 & 5.3 & 20.5 & $\mathrm{~B}+$ & single & urdu speaking & no & 95 & AA \\
\hline control & $18-23$ & female & 54 & 5.8 & 17.6 & O+ & single & urdu speaking & no & 98 & AA \\
\hline control & $18-23$ & female & 58 & 5.7 & 20 & O+ & single & urdu speaking & no & 82 & AA \\
\hline control & $24-28$ & male & 62 & 5.8 & 20.7 & O+ & married & baloch & no & 82 & AA \\
\hline control & $18-23$ & male & 72 & 5.8 & 24.1 & $\mathrm{~B}+$ & single & punjabi & no & 85 & AA \\
\hline control & $18-23$ & male & 67 & 5.1 & 21.1 & A+ & single & urdu speaking & no & 93 & AA \\
\hline control & $18-23$ & male & 63 & 5.9 & 20.5 & O+ & single & urdu speaking & no & 85 & AA \\
\hline control & $18-23$ & female & 57 & 5.2 & 22.9 & O+ & single & pathan & no & 84 & AA \\
\hline control & $18-23$ & male & 62 & 5.11 & 19 & O+ & single & punjabi & no & 82 & AA \\
\hline control & $18-23$ & female & 74 & 5.3 & 28.9 & $\mathrm{~B}+$ & married & urdu speaking & no & 71 & AA \\
\hline control & $29-33$ & female & 67 & 5.2 & 26.9 & O+ & married & others & no & 77 & AA \\
\hline control & $18-23$ & female & 57 & 5.2 & 22.9 & At & single & sindhi & no & 92 & gg \\
\hline control & $18-23$ & male & 100 & 6.1 & 23 & O+ & single & baloch & no & 91 & gg \\
\hline control & $18-23$ & female & 55 & 5.4 & 20.8 & $\mathrm{~B}+$ & single & punjabi & no & 64 & $\mathrm{Ag}$ \\
\hline
\end{tabular}




\begin{tabular}{|c|c|c|c|c|c|c|c|c|c|c|c|}
\hline control & $18-23$ & male & 73 & 5.9 & 23.7 & $\mathrm{~B}+$ & single & urdu speaking & no & 99 & gg \\
\hline control & $18-23$ & female & 55 & 5.5 & 20.1 & $\mathrm{~B}+$ & single & others & no & 86 & gg \\
\hline control & $18-23$ & female & 56 & 5.8 & 18.7 & $\mathrm{~B}+$ & single & punjabi & no & 80 & $\mathrm{Ag}$ \\
\hline control & $18-23$ & female & 55 & 5.3 & 21.4 & B- & single & sindhi & no & 90 & AA \\
\hline control & $18-23$ & male & 75 & 5.11 & 23 & A- & single & urdu speaking & no & 85 & AA \\
\hline control & $29-33$ & female & 90 & 5.6 & 32 & $\mathrm{~B}+$ & married & punjabi & no & 81 & AA \\
\hline control & $34-38$ & female & 80 & 5.6 & 28.4 & $\mathrm{~B}+$ & married & others & no & 82 & AA \\
\hline control & $18-23$ & female & 50 & 5.7 & 17.2 & AB- & single & urdu speaking & no & 85 & gg \\
\hline control & $18-23$ & male & 97 & 5.11 & 29.8 & $\mathrm{~B}+$ & single & urdu speaking & no & 72 & gg \\
\hline control & $24-28$ & male & 49 & 6 & 14.5 & $\mathrm{O}+$ & married & urdu speaking & no & 85 & $\mathrm{gg}$ \\
\hline control & $18-23$ & male & 75 & 5.4 & 28.3 & $\mathrm{~B}+$ & single & urdu speaking & no & 67 & gg \\
\hline control & $18-23$ & male & 55 & 5.7 & 18.9 & AB- & single & urdu speaking & no & 79 & gg \\
\hline control & $18-23$ & female & 64 & 5.4 & 24.2 & $0-$ & single & others & no & 74 & gg \\
\hline control & $24-28$ & female & 55 & 5.5 & 20.1 & B- & married & punjabi & no & 54 & $\mathrm{Ag}$ \\
\hline control & $24-28$ & male & 55 & 5.6 & 19.5 & AB- & married & others & no & 79 & AA \\
\hline control & $18-23$ & female & 55 & 5.6 & 19.5 & $0-$ & single & urdu speaking & no & 78 & AA \\
\hline control & $29-33$ & female & 102 & 5.4 & 38.5 & $\mathrm{~B}+$ & married & others & no & 79 & AA \\
\hline control & $18-23$ & male & 55 & 5.6 & 19.5 & $\mathrm{~B}+$ & single & urdu speaking & no & 63 & AA \\
\hline control & $18-23$ & male & 90 & 5.1 & 28.4 & AB- & single & urdu speaking & no & 69 & AA \\
\hline control & $34-38$ & female & 74 & 5.7 & 25.5 & $\mathrm{O}+$ & married & others & no & 64 & AA \\
\hline control & $24-28$ & male & 85 & 5.9 & 27.6 & B- & married & urdu speaking & no & 74 & gg \\
\hline control & $18-23$ & female & 59 & 5.7 & 20.3 & $\mathrm{AB}+$ & single & others & no & 98 & gg \\
\hline control & $18-23$ & male & 63 & 5.8 & 21 & $\mathrm{~B}+$ & single & urdu speaking & no & 77 & gg \\
\hline control & $34-38$ & female & 80 & 5.5 & 29.3 & $\mathrm{AB}+$ & married & urdu speaking & no & 89 & gg \\
\hline control & $29-33$ & female & 70 & 5.6 & 24.9 & $\mathrm{~B}+$ & married & urdu speaking & no & 86 & gg \\
\hline control & $29-33$ & female & 73 & 5.4 & 27.6 & $\mathrm{AB}+$ & married & sindhi & no & 98 & $\mathrm{gg}$ \\
\hline control & $24-28$ & male & 72 & 5.6 & 25.5 & $0-$ & single & others & no & 67 & gg \\
\hline control & $29-33$ & female & 85 & 5.5 & 31.1 & $\mathrm{AB}+$ & married & punjabi & no & 68 & gg \\
\hline control & $29-33$ & female & 85 & 5.3 & 33.1 & $\mathrm{~B}+$ & married & urdu speaking & no & 73 & gg \\
\hline control & $29-33$ & female & 58 & 5.5 & 21.1 & $\mathrm{~B}+$ & married & urdu speaking & no & 100 & AA \\
\hline control & $29-33$ & female & 58 & 5.5 & 21.1 & $\mathrm{AB}+$ & married & urdu speaking & no & 54 & gg \\
\hline control & $24-28$ & male & 72 & 5.6 & 25.5 & $\mathrm{~B}+$ & married & urdu speaking & no & 65 & AA \\
\hline control & $29-33$ & male & 84 & 5.8 & 28 & $\mathrm{O}+$ & married & baloch & no & 69 & AA \\
\hline control & $34-38$ & male & 80 & 5.1 & 25.3 & $0+$ & married & urdu speaking & no & 52 & AA \\
\hline control & $29-33$ & male & 79 & 5.1 & 24.8 & $\mathrm{O}+$ & married & sindhi & no & 75 & AA \\
\hline control & $29-33$ & male & 75 & 5.6 & 26.6 & $A+$ & married & sindhi & no & 93 & AA \\
\hline control & $29-33$ & male & 75 & 5.1 & 23.7 & $A+$ & married & sindhi & no & 78 & AA \\
\hline control & $29-33$ & male & 72 & 5.9 & 23.3 & $\mathrm{O}+$ & married & sindhi & no & 62 & AA \\
\hline control & $24-28$ & male & 85 & 5.1 & 26.8 & $A+$ & married & sindhi & no & 68 & $\mathrm{AA}$ \\
\hline
\end{tabular}




\begin{tabular}{|c|c|c|c|c|c|c|c|c|c|c|c|}
\hline control & $34-38$ & male & 83 & 5.7 & 28.6 & At & married & sindhi & no & 69 & AA \\
\hline control & $18-23$ & female & 67 & 5.4 & 25.2 & At & single & sindhi & no & 79 & AA \\
\hline control & $18-23$ & female & 70 & 5 & 30.1 & $\mathrm{~B}+$ & single & punjabi & no & 85 & AA \\
\hline control & $24-28$ & male & 85 & 5.9 & 27.6 & $\mathrm{~B}+$ & married & punjabi & no & 70 & $\mathrm{Ag}$ \\
\hline control & $24-28$ & male & 70 & 6 & 20.9 & $\mathrm{~B}+$ & married & punjabi & no & 97 & AA \\
\hline control & $18-23$ & female & 59 & 5.6 & 20.9 & $\mathrm{O}+$ & married & punjabi & no & 94 & $\mathrm{Ag}$ \\
\hline control & $34-38$ & female & 57 & 5 & 24.5 & O+ & married & pathan & no & 79 & $\mathrm{Ag}$ \\
\hline control & $18-23$ & female & 60 & 5 & 25.8 & A- & single & pathan & no & 76 & AA \\
\hline control & $24-28$ & male & 70 & 5.11 & 21.5 & B- & married & pathan & no & 96 & $\mathrm{gg}$ \\
\hline control & $24-28$ & male & 75 & 5.9 & 24.4 & At & married & pathan & no & 87 & AA \\
\hline control & $24-28$ & male & 82 & 5.7 & 28.3 & $\mathrm{~B}+$ & single & pathan & no & 89 & AA \\
\hline control & $24-28$ & male & 90 & 5.8 & 30.1 & $\mathrm{O}+$ & single & pathan & no & 74 & AA \\
\hline control & $24-28$ & male & 76 & 5.1 & 24 & $0-$ & single & pathan & no & 69 & AA \\
\hline control & $24-28$ & female & 70 & 5.4 & 26.4 & $\mathrm{AB}+$ & married & pathan & no & 95 & AA \\
\hline control & $24-28$ & female & 69 & 5.2 & 27.8 & $0-$ & married & baloch & no & 75 & AA \\
\hline control & $18-23$ & female & 65 & 5.7 & 22.4 & AB- & single & baloch & no & 77 & AA \\
\hline control & $18-23$ & female & 55 & 5.2 & 22.1 & $\mathrm{O}+$ & single & urdu speaking & no & 88 & AA \\
\hline control & $24-28$ & female & 68 & 5.5 & 24.9 & $\mathrm{O}+$ & single & urdu speaking & no & 83 & AA \\
\hline control & $24-28$ & female & 82 & 5.8 & 27.4 & $\mathrm{~B}+$ & married & others & no & 85 & AA \\
\hline control & $24-28$ & female & 85 & 5.7 & 29.3 & $\mathrm{~B}+$ & married & others & no & 84 & AA \\
\hline control & $34-38$ & male & 95 & 5.1 & 30 & $\mathrm{~B}+$ & married & others & no & 74 & AA \\
\hline control & $34-38$ & female & 60 & 5 & 25.8 & $\mathrm{O}+$ & married & others & no & 76 & $\mathrm{Ag}$ \\
\hline cases & $24-28$ & male & 79 & 6 & 23.6 & $\mathrm{O}+$ & married & urdu speaking & yes & 97 & AA \\
\hline cases & $24-28$ & male & 80 & 6.2 & 22.6 & $\mathrm{AB}+$ & married & urdu speaking & yes & 98 & AA \\
\hline cases & $18-23$ & male & 82 & 5.8 & 23.2 & $\mathrm{AB}+$ & single & urdu speaking & yes & 87 & AA \\
\hline cases & $18-23$ & male & 89 & 5.9 & 28.9 & At & single & punjabi & yes & 84 & AA \\
\hline cases & $24-28$ & male & 73 & 5.8 & 24.4 & At & single & punjabi & yes & 90 & AA \\
\hline cases & $24-28$ & male & 74 & 5 & 31.6 & $A+$ & single & punjabi & yes & 96 & AA \\
\hline cases & $34-38$ & male & 69 & 5.9 & 22.4 & $\mathrm{~B}+$ & married & punjabi & yes & 98 & AA \\
\hline cases & $18-23$ & male & 92 & 5.1 & 29 & $\mathrm{~B}+$ & single & punjabi & yes & 70 & $\mathrm{gg}$ \\
\hline cases & $18-23$ & male & 84 & 5.8 & 28.1 & $\mathrm{O}+$ & single & punjabi & yes & 89 & $\mathrm{gg}$ \\
\hline cases & $24-28$ & female & 80 & 5.2 & 32.2 & $\mathrm{~B}+$ & married & punjabi & yes & 82 & $\mathrm{gg}$ \\
\hline cases & $24-28$ & female & 82 & 5.5 & 30 & $\mathrm{~B}+$ & married & sindhi & yes & 79 & gg \\
\hline cases & $18-23$ & female & 69 & 5.6 & 24.5 & $\mathrm{~B}+$ & married & sindhi & yes & 70 & gg \\
\hline cases & $34-38$ & male & 76 & 5.8 & 25.4 & $\mathrm{~B}+$ & married & sindhi & yes & 80 & $\mathrm{gg}$ \\
\hline cases & $18-23$ & male & 70 & 5.8 & 23.4 & $\mathrm{AB}+$ & single & pathan & yes & 87 & $\mathrm{gg}$ \\
\hline cases & $29-33$ & male & 75 & 5.8 & 25.1 & A- & single & pathan & yes & 86 & $\mathrm{gg}$ \\
\hline cases & $29-33$ & male & 76 & 5.9 & 24.7 & At & single & pathan & yes & 86 & gg \\
\hline cases & 29-33 & male & 78 & 5.9 & 25.3 & $\mathrm{~B}+$ & single & punjabi & yes & 86 & $\mathrm{gg}$ \\
\hline cases & $29-33$ & male & 80 & 5.1 & 25.3 & $\mathrm{~B}+$ & married & punjabi & yes & 81 & AA \\
\hline
\end{tabular}




\section{Cureus}

\begin{tabular}{|c|c|c|c|c|c|c|c|c|c|c|c|}
\hline cases & $24-28$ & male & 81 & 5.1 & 25.5 & O+ & single & punjabi & yes & 90 & AA \\
\hline cases & $24-28$ & female & 69 & 5.3 & 26.9 & B- & married & punjabi & yes & 90 & AA \\
\hline cases & $24-28$ & female & 60 & 5.2 & 24.1 & O+ & married & punjabi & yes & 91 & AA \\
\hline cases & $24-28$ & male & 74 & 5.1 & 23.4 & $0-$ & married & urdu speaking & yes & 93 & AA \\
\hline cases & $24-28$ & male & 78 & 6 & 23.3 & $A+$ & married & urdu speaking & yes & 98 & AA \\
\hline cases & $24-28$ & male & 83 & 6.2 & 23.4 & $\mathrm{~B}+$ & married & urdu speaking & yes & 99 & AA \\
\hline cases & $29-33$ & male & 84 & 6 & 25.1 & $\mathrm{~B}+$ & married & urdu speaking & yes & 80 & AA \\
\hline cases & $29-33$ & male & 81 & 5.1 & 25.6 & $\mathrm{~B}+$ & married & urdu speaking & yes & 74 & AA \\
\hline cases & $18-23$ & male & 80 & 5.9 & 26 & $A+$ & single & urdu speaking & yes & 87 & AA \\
\hline cases & $18-23$ & female & 68 & 5.8 & 22.7 & $\mathrm{~B}+$ & single & urdu speaking & yes & 89 & AA \\
\hline cases & $18-23$ & female & 69 & 5.4 & 26.1 & $A+$ & single & punjabi & yes & 88 & AA \\
\hline cases & $34-38$ & female & 70 & 5.4 & 26.4 & $\mathrm{~B}+$ & married & punjabi & yes & 76 & AA \\
\hline cases & $34-38$ & male & 71 & 5.9 & 23.1 & O+ & married & punjabi & yes & 70 & AA \\
\hline cases & $34-38$ & male & 71 & 5.9 & 23.1 & O+ & married & punjabi & yes & 72 & AA \\
\hline cases & $29-33$ & male & 60 & 5.6 & 21.3 & O+ & single & others & yes & 65 & AA \\
\hline cases & $18-23$ & male & 70 & 5.8 & 23.4 & B- & single & others & yes & 69 & AA \\
\hline cases & $24-28$ & male & 86 & 5.9 & 27.9 & O+ & married & others & yes & 67 & $\mathrm{AA}$ \\
\hline cases & $18-23$ & male & 97 & 5.4 & 36.6 & $\mathrm{~B}+$ & single & others & yes & 96 & AA \\
\hline cases & $24-28$ & male & 98 & 5.9 & 31.8 & $\mathrm{~B}+$ & single & others & yes & 85 & gg \\
\hline cases & $24-28$ & male & 73 & 6 & 21.8 & $\mathrm{~A}+$ & single & punjabi & yes & 79 & gg \\
\hline cases & $24-28$ & female & 70 & 5.4 & 26.4 & $0-$ & married & punjabi & yes & 69 & gg \\
\hline cases & $24-28$ & female & 77 & 5.4 & 26 & At & married & sindhi & yes & 80 & $\mathrm{gg}$ \\
\hline
\end{tabular}

\section{TABLE 4: SPSS data for results}

SPSS: Statistical Package for the Social Sciences; BMI: body mass index

\begin{tabular}{|c|c|c|c|c|}
\hline GENOTYPE & GROUP & AGE & BMI & FBS \\
\hline aa & control & 23 & 20.5 & 95 \\
\hline aa & control & 22 & 17.6 & 98 \\
\hline aa & control & 23 & 20 & 82 \\
\hline aa & control & 28 & 20.7 & 82 \\
\hline aa & control & 18 & 24.1 & 85 \\
\hline aa & control & 18 & 21.1 & 93 \\
\hline aa & control & 18 & 20.5 & 85 \\
\hline aa & control & 20 & 22.9 & 84 \\
\hline aa & control & 22 & 19 & 82 \\
\hline aa & control & 23 & 28.9 & 71 \\
\hline aа & control & 30 & 26.9 & 77 \\
\hline gg & control & 22 & 22.9 & 92 \\
\hline
\end{tabular}




\section{Cureus}

\begin{tabular}{|c|c|c|c|c|}
\hline gg & control & 22 & 23 & 91 \\
\hline ag & control & 22 & 20.8 & 64 \\
\hline gg & control & 22 & 23.7 & 99 \\
\hline gg & control & 23 & 20.1 & 86 \\
\hline ag & control & 23 & 18.7 & 80 \\
\hline aa & control & 23 & 21.4 & 90 \\
\hline aa & control & 21 & 23 & 85 \\
\hline aa & control & 32 & 32 & 81 \\
\hline aa & control & 35 & 28.4 & 82 \\
\hline gg & control & 22 & 17.2 & 85 \\
\hline gg & control & 21 & 29.8 & 72 \\
\hline gg & control & 27 & 14.5 & 85 \\
\hline gg & control & 22 & 28.3 & 67 \\
\hline gg & control & 22 & 18.9 & 79 \\
\hline gg & control & 23 & 24.2 & 74 \\
\hline ag & control & 26 & 20.1 & 54 \\
\hline aa & control & 26 & 19.5 & 79 \\
\hline aa & control & 20 & 19.5 & 78 \\
\hline aa & control & 32 & 38.5 & 79 \\
\hline aa & control & 22 & 19.5 & 63 \\
\hline aa & control & 23 & 28.4 & 69 \\
\hline aa & control & 34 & 25.5 & 64 \\
\hline gg & control & 26 & 27.6 & 74 \\
\hline gg & control & 23 & 20.3 & 98 \\
\hline gg & control & 23 & 21 & 77 \\
\hline gg & control & 34 & 29.3 & 89 \\
\hline gg & control & 30 & 24.9 & 86 \\
\hline gg & control & 30 & 27.6 & 98 \\
\hline gg & control & 25 & 25.5 & 67 \\
\hline gg & control & 30 & 31.1 & 68 \\
\hline gg & control & 30 & 33.1 & 73 \\
\hline aa & control & 31 & 21.1 & 100 \\
\hline gg & control & 29 & 21.1 & 54 \\
\hline aa & control & 25 & 25.5 & 65 \\
\hline aa & control & 30 & 28 & 69 \\
\hline aa & control & 34 & 25.3 & 52 \\
\hline aa & control & 29 & 24.8 & 75 \\
\hline aa & control & 32 & 26.6 & 93 \\
\hline aa & control & 30 & 23.7 & 78 \\
\hline aа & control & 30 & 23.3 & 62 \\
\hline
\end{tabular}




\section{Cureus}

aa control

control

control

control

control

control

control

control

control

control

control

control

control

control

control

control

control

control

control

control

control

control

control

cases

cases

cases

cases

cases

cases

cases

cases

cases

cases

cases

cases

cases

cases

cases

cases
25

34

23

23

25

27

23

22

22

25

25

26

26

28

28

21

22

25

26

27

34

35

29

22

23

20

23

29

22

22

20

22

23

25
26.8

28.6

25.2

30.1

27.6

20.9

20.9

24.5

25.8

21.5

24.4

28.3

30.1

24

26.4

27.8

22.4

22.1

24.9

27.4

29.3

30

25.8

24.1

22.9

16.8

22.3

21.3

21.3

22.2

18.5

23.3

19.7

19.6

21.3

20.8

27

20.1

26.2
68

69

79

85

70

97

94

79

76

96

87

89

74

69

95

75

77

88

83

85

84

74

76

93

99

80

96

97

91

80

100

98

84

99

98

81

77

98

63 


\section{Cureus}

\begin{tabular}{|c|c|c|c|c|}
\hline $\mathrm{gg}$ & cases & 27 & 28.4 & 56 \\
\hline ag & cases & 23 & 26 & 84 \\
\hline ag & cases & 22 & 26 & 79 \\
\hline aa & cases & 34 & 25.9 & 64 \\
\hline gg & cases & 34 & 26.6 & 65 \\
\hline gg & cases & 27 & 31.9 & 77 \\
\hline ag & cases & 26 & 28.1 & 78 \\
\hline ag & cases & 22 & 26.4 & 85 \\
\hline ag & cases & 34 & 25.4 & 92 \\
\hline gg & cases & 30 & 28.2 & 88 \\
\hline gg & cases & 30 & 25.1 & 91 \\
\hline gg & cases & 25 & 25.1 & 76 \\
\hline gg & cases & 24 & 18.7 & 59 \\
\hline gg & cases & 26 & 17.5 & 77 \\
\hline $\mathrm{gg}$ & cases & 28 & 23 & 83 \\
\hline ag & cases & 29 & 18 & 77 \\
\hline ag & cases & 27 & 37.4 & 48 \\
\hline gg & cases & 27 & 28.2 & 93 \\
\hline gg & cases & 23 & 19.5 & 87 \\
\hline aa & cases & 27 & 23.6 & 97 \\
\hline aa & cases & 23 & 22.6 & 98 \\
\hline aa & cases & 26 & 23.2 & 87 \\
\hline aa & cases & 20 & 28.9 & 84 \\
\hline aa & cases & 28 & 24.4 & 90 \\
\hline aa & cases & 25 & 31.6 & 96 \\
\hline aa & cases & 34 & 22.4 & 98 \\
\hline gg & cases & 22 & 29 & 70 \\
\hline gg & cases & 23 & 28.1 & 89 \\
\hline gg & cases & 26 & 32.2 & 82 \\
\hline gg & cases & 27 & 30 & 79 \\
\hline gg & cases & 22 & 24.5 & 70 \\
\hline gg & cases & 34 & 25.4 & 80 \\
\hline gg & cases & 21 & 23.4 & 87 \\
\hline gg & cases & 32 & 25.1 & 86 \\
\hline gg & cases & 33 & 24.7 & 86 \\
\hline gg & cases & 31 & 25.3 & 86 \\
\hline aa & cases & 30 & 25.3 & 81 \\
\hline aa & cases & 25 & 25.5 & 90 \\
\hline aa & cases & 26 & 26.9 & 90 \\
\hline aa & cases & 27 & 24.1 & 91 \\
\hline
\end{tabular}




\section{Cureus}

\begin{tabular}{|c|c|c|c|c|}
\hline aa & cases & 27 & 23.4 & 93 \\
\hline aa & cases & 28 & 23.3 & 98 \\
\hline aa & cases & 28 & 23.4 & 99 \\
\hline aa & cases & 33 & 25.1 & 80 \\
\hline aa & cases & 32 & 25.6 & 74 \\
\hline aa & cases & 22 & 26 & 87 \\
\hline aa & cases & 23 & 22.7 & 89 \\
\hline aa & cases & 23 & 26.1 & 88 \\
\hline aa & cases & 34 & 26.4 & 76 \\
\hline aa & cases & 35 & 23.1 & 70 \\
\hline aa & cases & 35 & 23.1 & 72 \\
\hline aa & cases & 23 & 21.3 & 65 \\
\hline aa & cases & 23 & 23.4 & 69 \\
\hline aa & cases & 24 & 27.9 & 67 \\
\hline aa & cases & 22 & 36.6 & 96 \\
\hline gg & cases & 22 & 31.8 & 85 \\
\hline gg & cases & 26 & 21.8 & 79 \\
\hline gg & cases & 25 & 26.4 & 69 \\
\hline $\mathrm{gg}$ & cases & 26 & 29 & 80 \\
\hline
\end{tabular}

TABLE 5: SPSS data for ANOVA

SPSS: Statistical Package for the Social Sciences; BMI: body mass index; FBS: fasting blood sugar; ANOVA: analysis of variance 


\section{Cureus}

\begin{tabular}{|c|c|c|c|c|c|}
\hline Column1 & AGE & Frequency & Percent & Valid Percent & Cumulative Percent \\
\hline \multirow[t]{18}{*}{ Valid } & 18.00 & 3 & 2.0 & 2.0 & 2.0 \\
\hline & 20.00 & 5 & 3.3 & 3.3 & 5.3 \\
\hline & 21.00 & 4 & 2.7 & 2.7 & 8.0 \\
\hline & 22.00 & 24 & 16.0 & 16.0 & 24.0 \\
\hline & 23.00 & 24 & 16.0 & 16.0 & 40.0 \\
\hline & 24.00 & 2 & 1.3 & 1.3 & 41.3 \\
\hline & 25.00 & 12 & 8.0 & 8.0 & 49.3 \\
\hline & 26.00 & 14 & 9.3 & 9.3 & 58.7 \\
\hline & 27.00 & 12 & 8.0 & 8.0 & 66.7 \\
\hline & 28.00 & 7 & 4.7 & 4.7 & 71.3 \\
\hline & 29.00 & 5 & 3.3 & 3.3 & 74.7 \\
\hline & 30.00 & 11 & 7.3 & 7.3 & 82.0 \\
\hline & 31.00 & 2 & 1.3 & 1.3 & 83.3 \\
\hline & 32.00 & 5 & 3.3 & 3.3 & 86.7 \\
\hline & 33.00 & 2 & 1.3 & 1.3 & 88.0 \\
\hline & 34.00 & 13 & 8.7 & 8.7 & 96.7 \\
\hline & 35.00 & 5 & 3.3 & 3.3 & 100.0 \\
\hline & Total & 150 & 100.0 & 100.0 & \\
\hline
\end{tabular}

\section{TABLE 6: 18-23 age frequency separately}

We have shown the age range because the majority group we have taken to perceive the genetic role belonged to the 18-23 age group. We have attached the frequency file.

\section{Additional Information \\ Disclosures}

Human subjects: Consent was obtained by all participants in this study. Ethical Review committee Ziauddin University issued approval 1471019SZBC. The ERC Ziauddin University has reviewed this project in the meeting in October 2019 and gives approval to conduct this study. Animal subjects: All authors have confirmed that this study did not involve animal subjects or tissue. Conflicts of interest: In compliance with the ICMJE uniform disclosure form, all authors declare the following: Payment/services info: All authors have declared that no financial support was received from any organization for the submitted work. Financial relationships: All authors have declared that they have no financial relationships at present or within the previous three years with any organizations that might have an interest in the submitted work. Other relationships: All authors have declared that there are no other relationships or activities that could appear to have influenced the submitted work.

\section{Acknowledgements}

We gratefully acknowledge Ziauddin University for the support and for the facilitation in sampling. We also thank Dr. Aliya and Dr. Afreen from Ziauddin University for their assistance and guidance throughout the study.

\section{References}

1. Zano S, Baig S, Tahir B, Rebab Z-a: Parental history of type 2 diabetes mellitus: a lurking genetic threat . J Adv Med Med Res. 2020, 3:66-75. 10.9734/jammr/2020/v32i1230542

2. Hussain A, Ali I: Diabetes mellitus in Pakistan: a major public health concern . Arch Pharm Pract. 2016, 7:30- 
33.

3. Noreen Z, DeJesus J, Bhatti A, et al.: Epidemiological investigation of type 2 diabetes and Alzheimer's disease in a Pakistani population. Int J Environ Res Public Health. 2018, 15:1582. 10.3390/ijerph15081582

4. Ahmed MU, Seriwala HM, Danish SH, et al.: Knowledge, attitude, and self care practices amongst patients with type 2 diabetes in Pakistan. Glob J Health Sci. 2016, 8:1. 10.5539/gjhs.v8n7p1

5. Bragg F, Holmes MV, Iona A, et al.: Association between diabetes and cause-specific mortality in rural and urban areas of China. JAMA. 2017, 17:280-289. 10.1001/jama.2016.19720

6. Khorrami Z, Yarahmadi S, Etemad K: Urban-rural differences in the prevalence of self-reported diabetes and its risk factors: the WHO STEPS Iranian noncommunicable disease risk factor surveillance in 2011. Iran J Med Sci. 2017, 42:481-487.

7. Mohiuddin AK: Diabetes fact: Bangladesh perspective. Int J Diabetes Res. 2019, 24:14-20.

8. Heneghan C, Blacklock C, Perera R, et al.: Evidence for non-communicable diseases: analysis of Cochrane reviews and randomised trials by World Bank classification. BMJ Open. 2013, 3 :e003298. 10.1136/bmjopen2013-003298

9. Khan F, Ahmed W, Najmi A: Managing plastic waste disposal by assessing consumers' recycling behavior: the case of a densely populated developing country. Environ Sci Pollut Res. 2019, 26:33054-33066. 10.1007/s11356-019-06411-4

10. Aamir AH, Ul-Haq Z, Mahar SA, et al.: Diabetes Prevalence Survey of Pakistan (DPS-PAK): prevalence of type 2 diabetes mellitus and prediabetes using HbA1c: a population-based survey from Pakistan. BMJ Open. 2019, 9:e025300. 10.1136/bmjopen-2018-025300

11. Meo SA, Zia I, Bukhari IA, Arain SA: Type 2 diabetes mellitus in Pakistan: current prevalence and future forecast. J Pak Med Assoc. 2016, 66:1637-1642.

12. Zhang Y, Santosa A, Wang N, et al.: Prevalence and the association of body mass index and other risk factors with prediabetes and type 2 diabetes among 50,867 adults in China and Sweden: a cross-sectional study. Diabetes Ther. 2019, 10:2061-2077. 10.1007/s13300-019-00690-3

13. Fogarty MP, Panhuis TM, Vadlamudi S, Buchkovich ML, Mohlke KL: Allele-specific transcriptional activity at type 2 diabetes-associated single nucleotide polymorphisms in regions of pancreatic islet open chromatin at the JAZF1 locus. Diabetes. 2013, 62:1756-1762. 10.2337/db12-0972

14. Sohani ZN, Deng WQ, Pare G, Meyre D, Gerstein HC, Anand SS: Does genetic heterogeneity account for the divergent risk of type 2 diabetes in South Asian and white European populations?. Diabetologia. 2014, 57:2270-2281. 10.1007/s00125-014-3354-1

15. Alharbi KK, Khan IA, Syed R, Alharbi FK, Mohammed AK, Vinodson B, Al-Daghri NM: Association of JAZF1 and TSPAN8/LGR5 variants in relation to type 2 diabetes mellitus in a Saudi population. Diabetol Metab Syndr. 2015, 7:92. 10.1186/s13098-015-0091-7

16. Stančáková A, Kuulasmaa T, Paananen J, et al.: Association of 18 confirmed susceptibility loci for type 2 diabetes with indices of insulin release, proinsulin conversion, and insulin sensitivity in 5,327 nondiabetic Finnish men. Diabetes. 2009, 58:2129-2136. 10.2337/db09-0117

17. Rees SD, Hydrie MZ, Shera AS, et al.: Replication of 13 genome-wide association (GWA)-validated risk variants for type 2 diabetes in Pakistani populations. Diabetologia. 2011, 54:1368-1374. 10.1007/s00125011-2063-2

18. Dietrich S, Jacobs S, Zheng JS, Meidtner K, Schwingshackl L, Schulze MB: Gene-lifestyle interaction on risk of type 2 diabetes: a systematic review. Obes Rev. 2019, 20:1557-1571. 10.1111/obr.12921

19. Omori S, Tanaka Y, Horikoshi M, et al.: Replication study for the association of new meta-analysis-derived risk loci with susceptibility to type 2 diabetes in 6,244 Japanese individuals. Diabetologia. 2009, 52:15541560. 10.1007/s00125-009-1397-5

20. Liao ZZ, Wang YD, Qi XY, Xiao X-H: JAZF1, a relevant metabolic regulator in type 2 diabetes . Diabetes Metab Res Rev. 2019, 35:e3148. 10.1002/dmrr.3148

21. Rong R, Hanson RL, Ortiz D, et al.: Association analysis of variation in/near FTO, CDKAL1, SLC30A8, HHEX, EXT2, IGF2BP2, LOC387761, and CDKN2B with type 2 diabetes and related quantitative traits in Pima Indians. Diabetes. 2009, 58:478-488. 10.2337/db08-0877

22. Ng MC, Park KS, Oh B, et al.: Implication of genetic variants near TCF7L2, SLC30A8, HHEX, CDKAL1, CDKN2A/B, IGF2BP2, and FTO in type 2 diabetes and obesity in 6,719 Asians. Diabetes. 2008, 57:2226-2233. $10.2337 / \mathrm{db} 07-1583$

23. Bjerregaard LG, Jensen BW, Ängquist L, Osler M, Sørensen TIA, Baker JL: Change in overweight from childhood to early adulthood and risk of type 2 diabetes. N Engl J Med. 2018, 378:1302-1312. 10.1056/NEJMoa1713231

24. Huang X, Liu G, Guo J, Su Z: The PI3K/AKT pathway in obesity and type 2 diabetes . Int J Biol Sci. 2018, 14:1483-1496. 10.7150/ijbs.27173

25. Kong X, Xing X, Zhang X, Hong J, Yang W: Early-onset type 2 diabetes is associated with genetic variants of $\beta$-cell function in the Chinese Han population. Diabetes Metab Res Rev. 2020, 36:e3214. 10.1002/dmrr.3214

26. Eizirik DL, Pasquali L, Cnop M: Pancreatic $\beta$-cells in type 1 and type 2 diabetes mellitus: different pathways to failure. Nat Rev Endocrinol. 2020, 16:349-362.

27. Kobiita A, Godbersen S, Araldi E, et al.: The diabetes gene JAZF1 is essential for the homeostatic control of ribosome biogenesis and function in metabolic stress. Cell Rep. 2020, 7:107846.

10.1016/j.celrep.2020.107846

28. Meng F, Lin Y, Yang M, Li M, Yang G, Hao P, Li L: JAZF1 inhibits adipose tissue macrophages and adipose tissue inflammation in diet-induced diabetic mice. Biomed Res Int. 2018, 2018:4507659. 10.1155/2018/4507659

29. Geng T, Huang T: Gene-environment interactions and type 2 diabetes. Asia Pac J Clin Nutr. 2020, 29:220.

30. Abdullah N, Murad NA, Haniff EAM, et al.: Predicting type 2 diabetes using genetic and environmental risk factors in a multi-ethnic Malaysian cohort. Public Health. 2017, 149:31-38. 10.1016/j.puhe.2017.04.003 